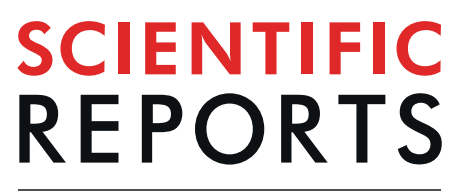

natureresearch

\title{
OPEN Muscle attachment site patterns for species determination in West Palaearctic Wohlfahrtia (Diptera: Sarcophagidae) of medical and veterinary importance
}

\author{
Senta Niederegger ${ }^{1 *}$, Kamran Akbarzadeh ${ }^{2} \&$ Krzysztof Szpila ${ }^{3}$ \\ The flesh fly genus Wohlfahrtia Brauer \& Bergenstamm contains at least six species of medical and \\ veterinary importance. Traditional methods of species identification in specimens of Wohlfahrtia, \\ however, are restricted mostly to adult forms. Muscle attachment site (MAS) patterns allow for species \\ determination in larval forms. MAS patterns in third instar larvae of six common West Palearctic \\ species of Wohlfahrtia have been analyzed for this study. As in previously investigated Calliphoridae \\ and Sarcophagidae, MAS patterns were found to be species specific. A genus pattern was established \\ to be used as base for comparison in further species determination. For the first time a tool is provided \\ for species identification of such broad range in larvae of Wohlfahrtia species. Wohlfahrtia patterns \\ are composed of a significantly higher number of MAS than patterns found in Sarcophaga. Specifics of \\ the six species analyzed are explained in detail. The larvae of the well-known species W. magnifica, an \\ obligate traumatic myiasis agent, had to be excluded from the analysis as a great number of spines on \\ the outside obscure muscle attachment sites on the inside of the cuticle.
}

The flesh fly genus Wohlfahrtia Brauer \& Bergenstamm, 1889 contains 24 species distributed mostly in the Palaearctic region ${ }^{1}$. Several of them are of medical and veterinary importance, as they are either facultative or obligate myiasis producers in man or other mammals ${ }^{2}$. The best known is Wohlfahrtia magnifica, traumatic myiasis agent, common and widely distributed in the Mediterranean Basin and the Middle East ${ }^{3}$. Necrophagous species of Wohlfahrtia may act as facultative parasites but their larvae usually develop in carrion ${ }^{4-8}$. Genus Wohlfahrtia belongs to the subfamily Paramacronychiinae traditionally treated as sister to Sarcophaginae $e^{9,10}$ but recent molecular studies point to their closer affinity to the subfamily Miltogramminae ${ }^{11-13}$.

Traditional methods of species identification in specimens of Wohlfahrtia have been applied mostly to adult forms ${ }^{14,15}$, because diagnostic data from preimaginal stages is available only for a few species ${ }^{16-20}$. Molecular data relevant for species identification are limited to eight species, including five species studied in the present paper ${ }^{5,12,21}$. However, available sequences refer to various genes (e.g. cytB, COI) and their limited variation may be insufficient for reliable species identification as has been demonstrated for the flesh fly genus Sarcophaga Meigen $^{22}$.

The method of comparing muscle attachment site (MAS) patterns has proved to be powerful in late instar larvae of forensically important Calliphoridae ${ }^{23-25}$ and Sarcophagidae ${ }^{26}$. The aim of this study was to further extend the method for the six most common species of the western Palaearctic Wohlfahrtia (Fig. 1). The species were chosen because they are known to be obligate or facultative myiasis agents and necrophages with confirmed or potential forensic importance. Furthermore, different feeding habits of facultative parasites/necrophages and obligate parasitic larvae (W. magnifica) could be reflected in diverging MAS patterns.

\footnotetext{
${ }^{1}$ Department of Forensic Entomology, Institute of Legal Medicine at the University Hospital Jena, 07740, Jena, Germany. ${ }^{2}$ Department of Medical Entomology \& Vector Control, School of Public Health, Tehran University of Medical Sciences, Tehran, Iran. ${ }^{3}$ Department of Ecology and Biogeography, Faculty of Biological and Veterinary Sciences, Nicolaus Copernicus University, Lwowska 1, 87-100, Toruń, Poland. *email: senta.niederegger@med.uni-jena.de
} 


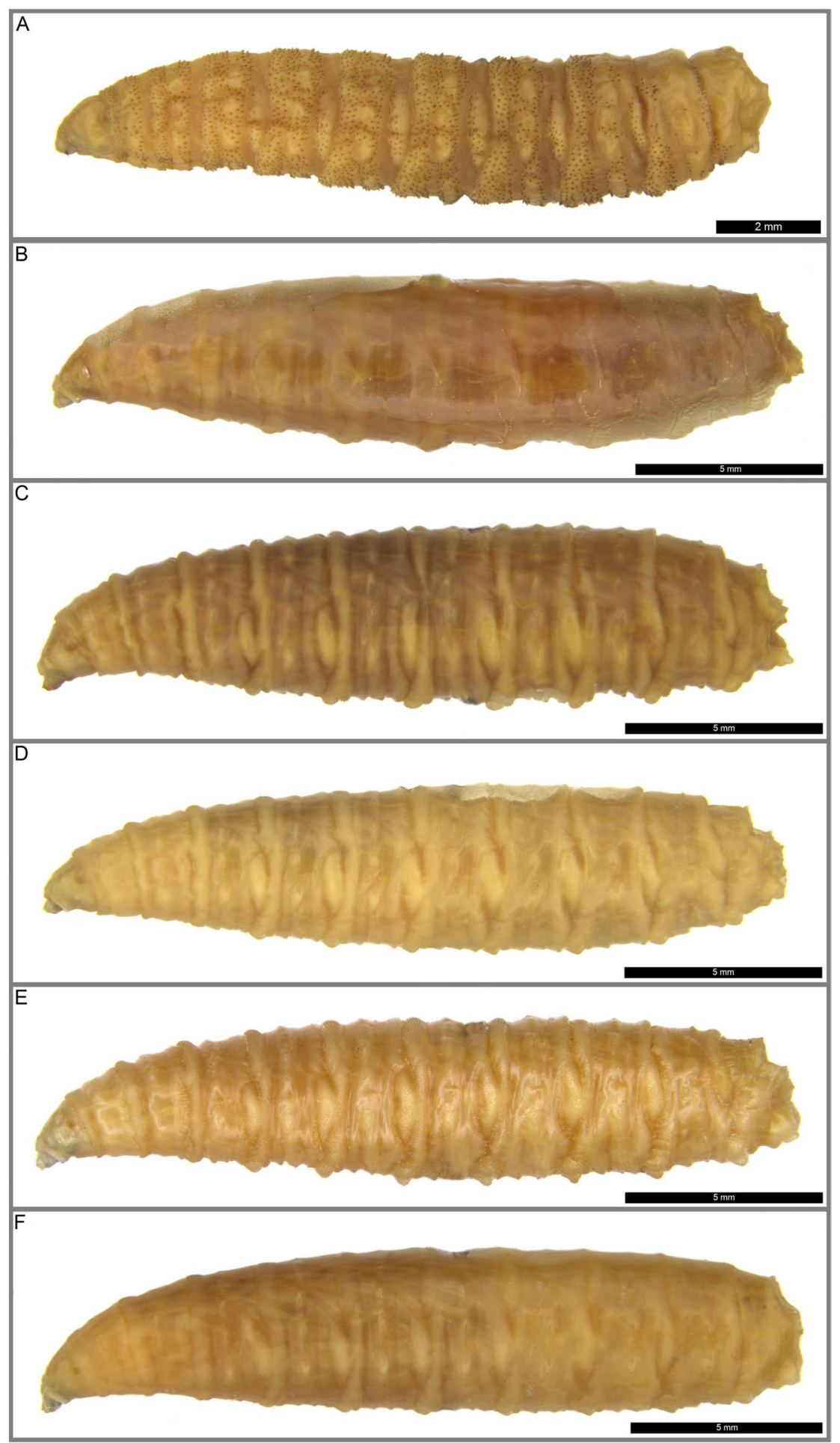

Figure 1. Habitus of Wohlfahrtia larvae studied: (A) - W. magnifica, (B) - W. bella, (C) - W. indigens, (D) - W. nuba, (E) - W. trina, (F) - W. villeneuvi.

\section{Results}

The number of MAS for body segments 2-4, (i.e., thoracic segments 2-3 and abdominal segment 1) (Fig. 2), ranged from 171 to 234 (Table 1). The lowest total number of MAS was found in an individual of W. indigens and the highest number was found in W. trina. The smallest individuals investigated belonged to W. indigens, and the largest to W. bella (Table 1). Individuals of Wohlfahrtia magnifica (Schiner, 1862) (screwworm fly) $(\mathrm{n}=13)$, the only obligate parasite included in this study, could not be analyzed as sclerotized spines on the cuticle obscured the MAS pattern (Fig. 2B). 


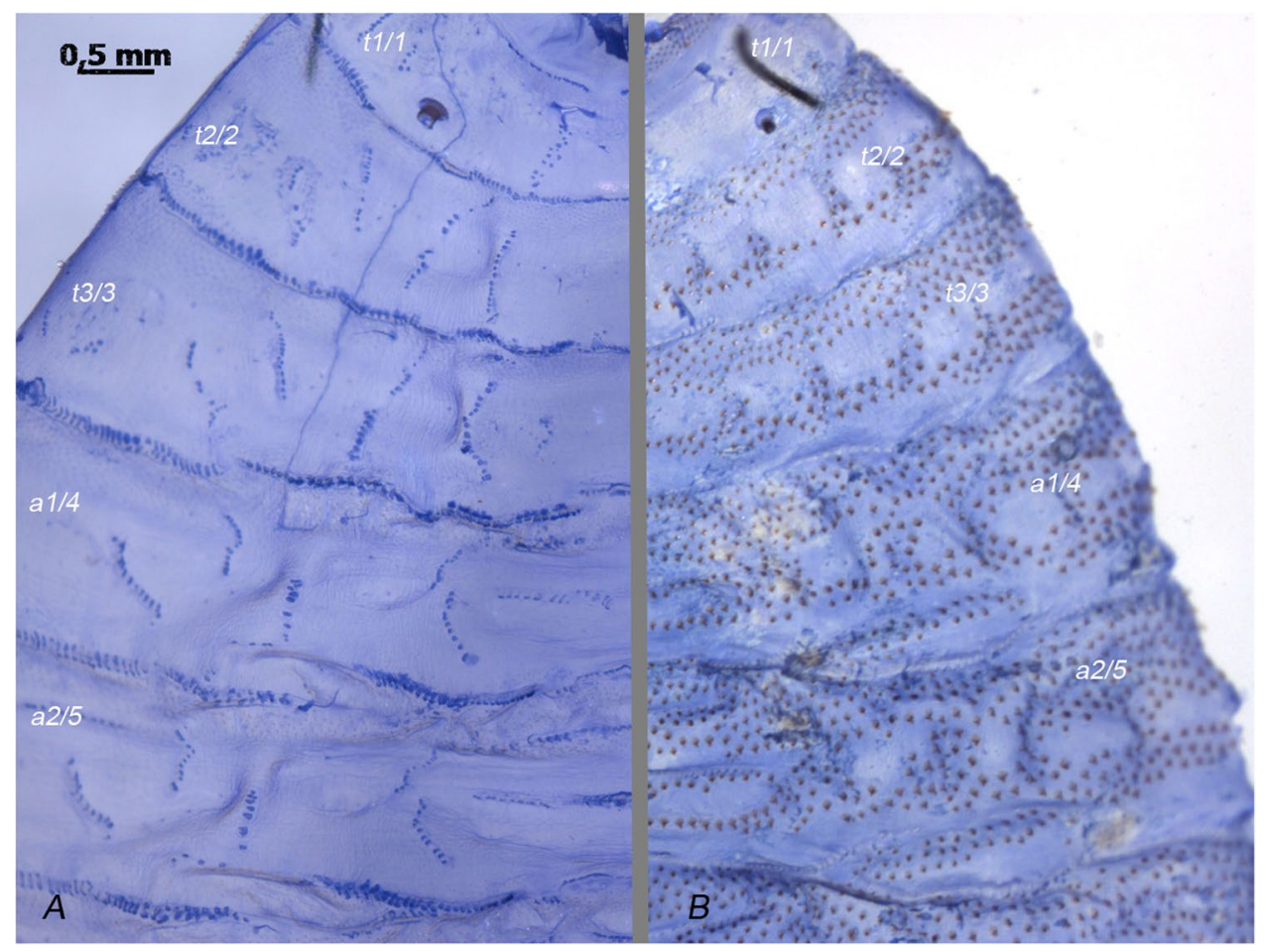

Figure 2. Segments 2-5 of Wohlfahrtia third instar larvae, cuticula only, dyed with Coomassie-brillant blue solution 1\%: (A) - W. trina, MAS pattern clearly visible, (B) - W. magnifica, MAS pattern obscured by sclerotized spines, $\mathrm{t}=$ thoracic segment, $\mathrm{a}=$ abdominal segment and numbers for plain designation.

\begin{tabular}{|l|l|l|l|l|l|}
\hline & W. bella & W. indigens & W. nuba & W. trina & W. villeneuvi \\
\hline Mean length $[\mathrm{mm}]$ & $19.11( \pm 1.52)$ & $15.16( \pm 0.96)$ & $16.77( \pm 1,06)$ & $18.57( \pm 0.95)$ & $17.11( \pm 1.3)$ \\
\hline \#MAS in 3 hemisegments & $191-223$ & $171-206$ & $175-206$ & $190-234$ & $174-219$ \\
\hline
\end{tabular}

Table 1. Average size of Wohlfahrtia larvae $( \pm S T D)$ compared to the ranges in numbers of MAS in 3 hemisegments.

The average number of MAS per hemisegment over all larvae was $55( \pm 6)$ for segment $2,66( \pm 6)$ for segment 3 and $77( \pm 6)$ for segment 4 . The numbers of MAS in pattern rows are consistent in most cases (Table 2). Rows with deviations (framed) can therefore be of important assistance for species determination.

Deviations in pattern rows usually showed no more than two MAS above or below the average count for the genus. Deviations above average were predominantly found in $W$. bella, which comprised the largest larvae investigated. Wohlfahrtia indigens, comprising the smallest larvae, showed only one and W. villeneuvi showed no such deviations (Table 2). Only one deviation was found with three MAS below the average genus count. This observation was made in $W$. nuba, which also presented five locations with deviations of 2 MAS below average count for the genus.

The genus pattern, generated from five species of the genus Wohlfahrtia investigated in this study, is the base of comparison for the researcher in order to distinguish larvae of Wohlfahrtia from larvae of Sarcophaga. The species can then be identified using the species patterns which are described in comparison to the genus pattern in the following.

Genus pattern $(\mathrm{n}=56)$ (Fig. 3$)$.

The genus pattern contains MAS in all numbered rows of segments 2-4 (or thoracic segments 2-3 and abdominal segment 1), no void spaces are present. Row 2.1 is very short and dot-like in appearance. Rows $2.2,2.4$ and 2.5 are short vertical rows, whereas row 2.3 is tripartite with a bend in the upper half. Rows 2.4 and 2.5 are shorter compared to rows 2.3 , giving the overall pattern a step-like appearance.

The central rows 3.1 in segment 3 are pointing their convex parts at each other like inverted brackets while row 3.2 encloses the two small patterns like big closing brackets. Row 3.3 is almost straight with an angle of about 30 degrees to the midline. 3.4 is $\mathrm{z}$-shaped on the left hemisegment but s-shaped on the right hemisegment, whereas 3.5 is the opposite: s-shaped on the left and z-shaped on the right side. The step-like appearance is maintained as in segment 2.

$4.1 \mathrm{~b}$ comprises two short mirrored horizontal rows in the middle. 4.1a is composed of two short mirrored horizontal rows divided by a small horizontal row in the middle. Rows 4.2 are again tripartite similar to rows 2.3. 4.3 is L-shaped, 4.4 and 4.5 are almost mirrored bent vertical rows but 4.5 is longer than 4.4 . The step-like appearance is again maintained in this segment as well.

Wohlfahrtia bella (Macquart, 1839) $(\mathrm{n}=11)$ (Fig. 4). 


\begin{tabular}{|c|c|c|c|c|c|c|c|}
\hline Row & 2.1 & \begin{tabular}{|l|l} 
& 2.2
\end{tabular} & 2.3 & \begin{tabular}{|l|l} 
& 2.4
\end{tabular} & \multicolumn{3}{|l|}{2.5} \\
\hline Genus & $2( \pm 1.1)$ & $16( \pm 2.1)$ & $15( \pm 2.7)$ & $12( \pm 1,9)$ & \multicolumn{3}{|l|}{$11( \pm 2.1)$} \\
\hline W. bella & $2( \pm 0.8)$ & $16( \pm 1.1)$ & $17( \pm 1.3)$ & $13( \pm 1.2)$ & \multicolumn{3}{|l|}{$10( \pm 1.5)$} \\
\hline W. indigens & $2( \pm 0.6)$ & $14( \pm 1.4)$ & $14( \pm 2.4)$ & $12( \pm 2.2)$ & \multicolumn{3}{|l|}{$11( \pm 0.7)$} \\
\hline W. nuba & $0( \pm 0.0)$ & $14( \pm 0.5)$ & $15( \pm 2.4)$ & $12( \pm 1.9)$ & \multicolumn{3}{|l|}{$10( \pm 0.5)$} \\
\hline W. trina & $3( \pm 1.0)$ & $18( \pm 2.1)$ & $15( \pm 3.2)$ & $12( \pm 1.6)$ & \multicolumn{3}{|l|}{$13( \pm 2.1)$} \\
\hline W. villeneuvi & $2( \pm 1.4)$ & $15( \pm 2.0)$ & $14( \pm 2.5)$ & $13( \pm 2.3)$ & \multicolumn{3}{|l|}{$11( \pm 2.5)$} \\
\hline Row & 3.1 & \begin{tabular}{|l|}
3.2 \\
\end{tabular} & 3.3 & \begin{tabular}{|l|}
3.4 \\
\end{tabular} & \multicolumn{3}{|l|}{3.5} \\
\hline Genus & $6( \pm 0.9)$ & $19( \pm 2.2)$ & $17( \pm 2.5)$ & $13( \pm 1.7)$ & \multicolumn{3}{|l|}{$12( \pm 1.3)$} \\
\hline W. bella & $7( \pm 0.7)$ & $19( \pm 1.5)$ & $19( \pm 2.2)$ & $15( \pm 1.7)$ & \multicolumn{3}{|l|}{$12( \pm 0.8)$} \\
\hline W. indigens & $6( \pm 0.8)$ & $18( \pm 2.3)$ & $17( \pm 2.6)$ & $12( \pm 1.4)$ & \multicolumn{3}{|l|}{$12( \pm 1.3)$} \\
\hline W. nuba & $5( \pm 0.8)$ & $17( \pm 1.7)$ & $15( \pm 1.4)$ & $13( \pm 1.5)$ & \multicolumn{3}{|l|}{$12( \pm 0.9)$} \\
\hline W. trina & $5( \pm 0.6)$ & $19( \pm 2.2)$ & $18( \pm 2.8)$ & $13( \pm 1.7)$ & \multicolumn{3}{|l|}{$13( \pm 1.4)$} \\
\hline W. villeneuvi & $6( \pm 0.8)$ & $19( \pm 2.5)$ & $16( \pm 2.0)$ & $12( \pm 1.3)$ & \multicolumn{3}{|l|}{$12( \pm 1.2)$} \\
\hline Row & 4.1a_center & 4.1a_side & $4.1 \mathrm{~b}$ & 4.2 & 4.3 & 4.4 & 4.5 \\
\hline Genus & $7( \pm 2.5)$ & $9( \pm 1.5)$ & $6( \pm 1.7)$ & $25( \pm 2.4)$ & $14( \pm 2.2)$ & $11( \pm 1.8)$ & $13( \pm 1.5)$ \\
\hline W. bella & $7( \pm 1.9)$ & $9( \pm 1.2)$ & $7( \pm 1.3)$ & $26( \pm 2.3)$ & $16( \pm 1.1)$ & $12( \pm 1.1)$ & $13( \pm 1.8)$ \\
\hline W. indigens & $7( \pm 2.3)$ & $7( \pm 1.0)$ & $6( \pm 1.4)$ & $24( \pm 1.8)$ & $13( \pm 1.1)$ & $10( \pm 0.7)$ & $12( \pm 1.2)$ \\
\hline W. nuba & $8( \pm 2.7)$ & $7( \pm 1.2)$ & $6( \pm 0.9)$ & $22( \pm 2.5)$ & $13( \pm 1.1)$ & $11( \pm 0.8)$ & $12( \pm 1.0)$ \\
\hline W. trina & $8( \pm 3.1)$ & $9( \pm 1.9)$ & $6( \pm 1.0)$ & $26( \pm 1.9)$ & $15( \pm 2.7)$ & $11( \pm 1.4)$ & $13( \pm 1.2)$ \\
\hline W. villeneuvi & $7( \pm 3.0)$ & $9( \pm 1.2)$ & $7( \pm 3.0)$ & $25( \pm 2.9)$ & $14( \pm 1.0)$ & $11( \pm 1.6)$ & $13( \pm 1.7)$ \\
\hline
\end{tabular}

Table 2. Average numbers of MAS per row structure for five Wohlfahrtia species and an average for the genus $( \pm \mathrm{STD})$. Italic values indicate most obvious deviations from genus pattern numbers.

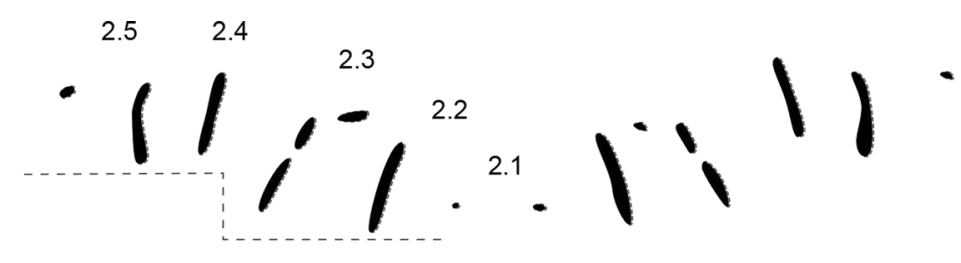

3.4

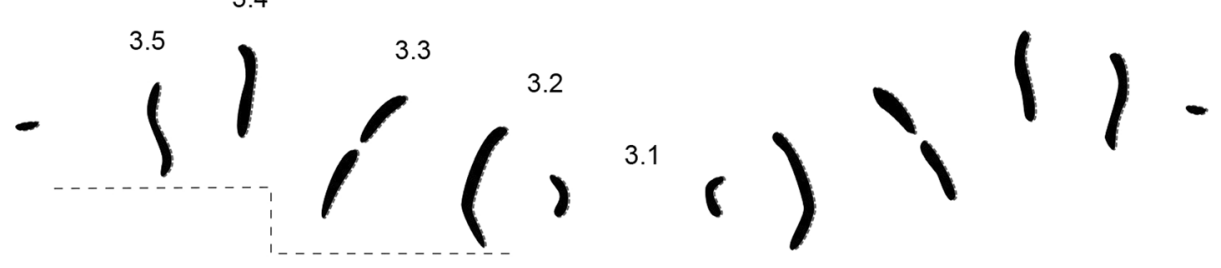

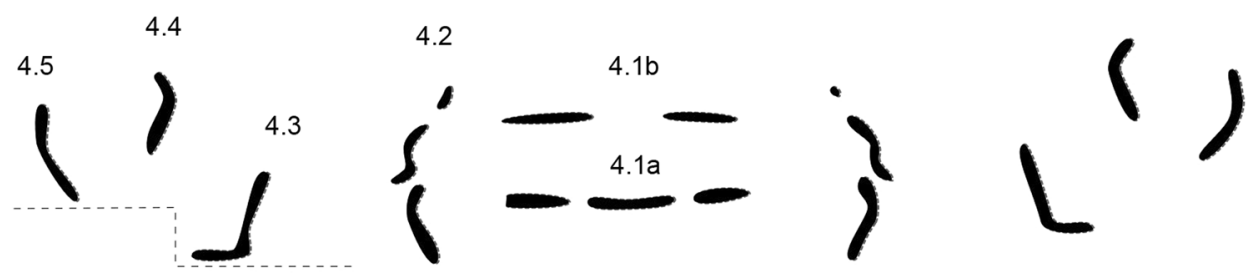

Figure 3. Genus pattern for Wohlfahrtia composed of 56 individual MAS patterns of W. bella, W. indigens, $W$. nuba, W. trina, W. villeneuvi. Rows are labeled according to their location on and affiliation with a segment (e.g. $2.1=$ central row in segment $2,4.5=$ most peripheral row in segment 4 ), dashed line $=$ step-like appearance of pattern.

The most obvious difference of $W$. bella compared to the genus pattern is a separation in rows 4.3 (arrows). The other rows correspond to the genus pattern, although variations can be found in one or the other half of a segment, but not in both.

Wohlfahrtia indigens Villeneuve, $1928(\mathrm{n}=10)$ (Fig. 5). 


\section{$2.5 \quad 2.4$ \\ 11,9311}

3.4
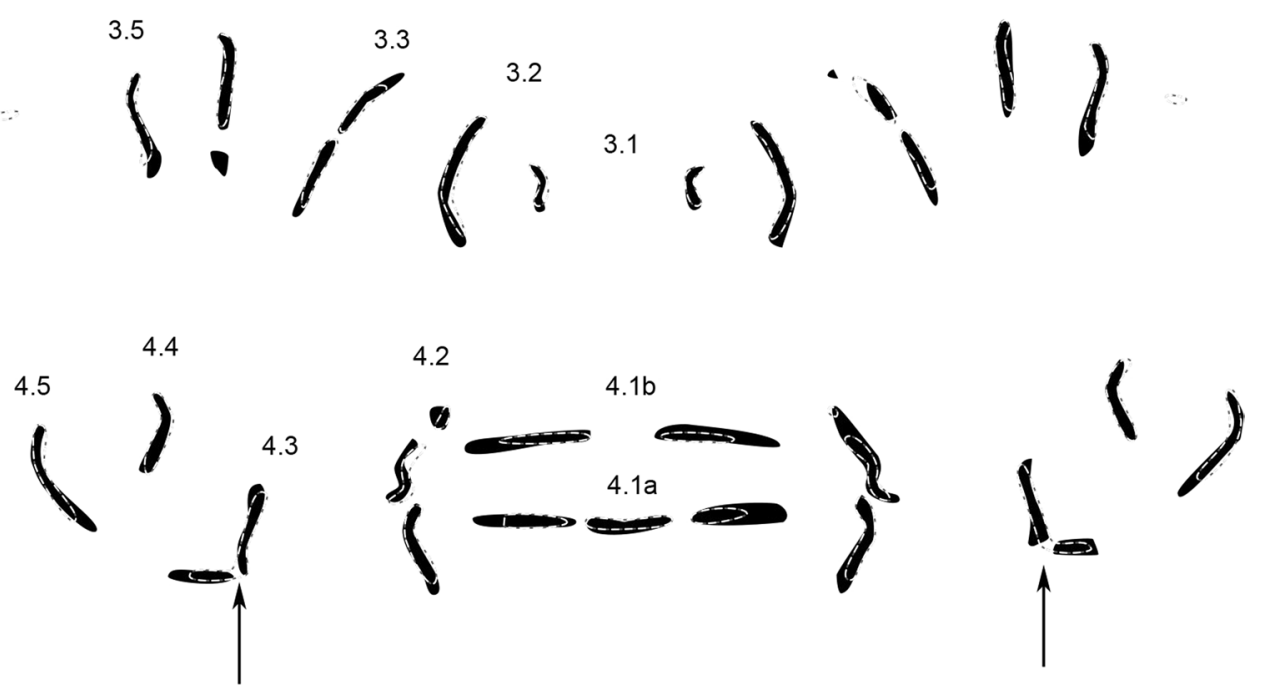

Figure 4. Condensed MAS pattern for Wohlfarthia bella (solid structures) superimposed with outlines of the genus pattern (dotted lines). Numbers indicate rows of transversal muscle attachment site patterns according to their location on and affiliation with a segment. Arrows indicate important differences compared to genus pattern.

Central row 4.1a lacks a distinct division between the center and the right side. Row 4.2 has only two, not three parts (arrows), eluding the trisection as seen in the genus pattern. The other rows of all segments line up almost perfectly with the genus pattern.

Wohlfahrtia nuba (Wiedemann, 1830) ( $\mathrm{n}=11)$ (Fig. 6).

Wohlfahrtia nuba is almost a combination of W. bella (Fig. 3) and W. indigens (Fig. 4), as both distinctions of these species are present. The top parts of row 4.2 are missing (arrows), eluding the trisection as seen in the genus pattern, and rows 4.3 have a separation (arrows). Furthermore, row 2.1 is completely missing in $W$. nuba.

Wohlfahrtia trina (Wiedemann, 1830) $(\mathrm{n}=12)$ (Fig. 7).

In W. trina, similar to W. villeneuvi (Fig. 7) and W. indigens (Fig. 4), row 4.1a is not tripartite as in the genus pattern. In $W$. trina however, the parts of 4 .1 a have merged into a single row without any separation. Row 2.2 is longer than in the genus pattern. Other differences are not consistent between the two sides of the segments.

Wohlfahrtia villeneuvi Salem, $1938(\mathrm{n}=12)$ (Fig. 8).

The most obvious difference in $W$. villeneuvi as compared to the genus pattern can be found in row 4.1a, where the partition is in the middle of two parts instead of a trisection with one central part. Almost all rows of segment 2 are slightly longer than in the genus pattern and row 2.2 is more curved. The rows of segment 3 correspond to those of the genus pattern.

Comparison of Wohlfahrtia and Sarcophaga. In comparison to the genus pattern of Sarcophaga (see Niederegger et al. $2016^{26}$ ), the rows appear shorter and narrower in the genus pattern of Wohlfahrtia. Nevertheless, the number of MAS is significantly higher in all rows in Wohlfahrtia (non-parametric Mann-Whitney U test, $\mathrm{p}<0.05$ ) (Table 3) with an average total number of MAS for three hemisegments of 206 in Wohlfahrtia and 163 in Sarcophaga. The trisection of rows 2.3 and 4.2 as well as the bisection of row 3.2 are the most obvious differences between the genera (Fig. 9).

\section{Discussion}

We studied facultative parasites/necrophages and one obligate parasite (W. magnifica) a serious traumatic myiasis agent of humans and animals ${ }^{3}$.

The parasite, $W$. magnifica, seems to need additional passive mechanisms to be able to support an obligate parasitic lifestyle, expressed by the bands of sclerotized spines found on the interband surface of segments (Fig. 1A). These spines unfortunately obscure the MAS patterns on the inside of the cuticula, which prevented the analysis (Fig. 2B). In a future endeavor, a method needs to be found to elude such obstacles by clearing pigments or using a different dyeing method. The passive mechanism provided by the spines could even have caused a reduction of MAS. 


$$
\begin{aligned}
& \text { "i" } \\
& \text { "i }
\end{aligned}
$$

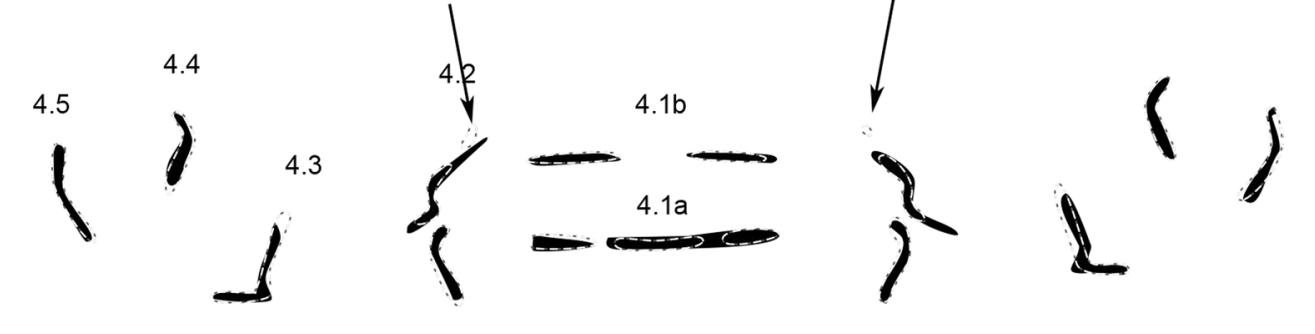

$$
\begin{aligned}
& \text { “ } 11,21^{\prime \prime} \\
& \text {. }
\end{aligned}
$$

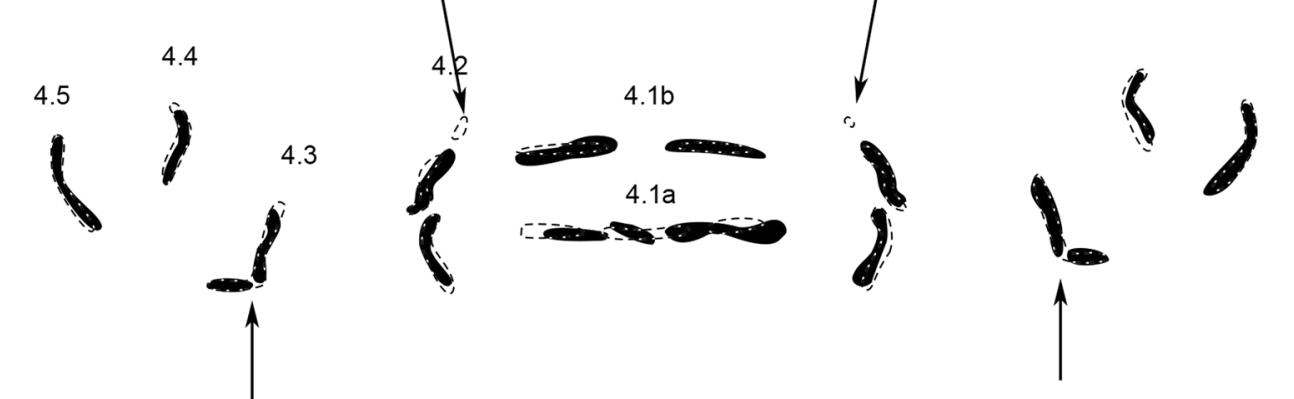



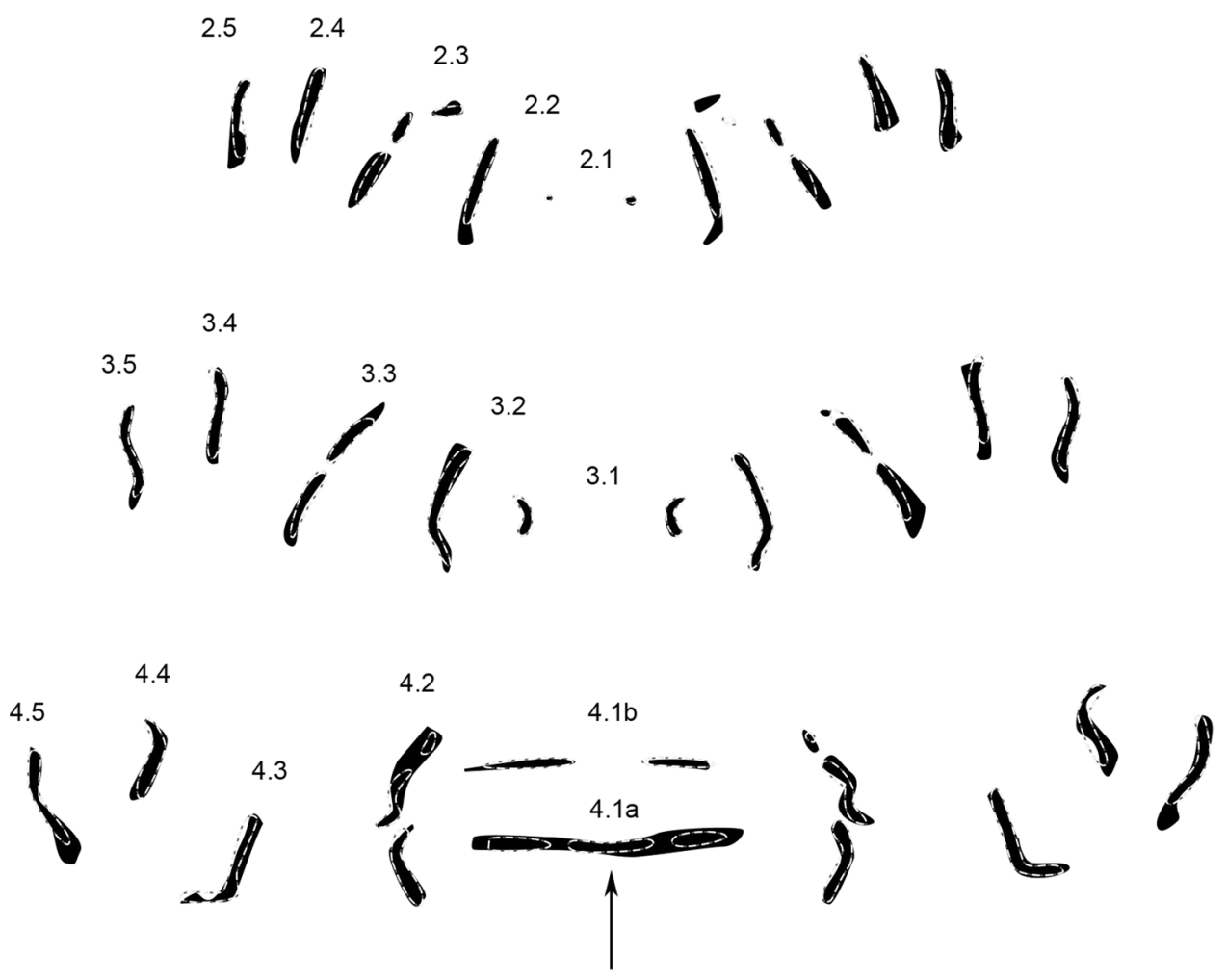

Figure 7. Condensed MAS pattern for Wohlfarthia trina (solid structures) superimposed with outlines of the genus pattern (dotted lines). Numbers indicate rows of transversal muscle attachment site patterns according to their location on and affiliation with a segment. Arrows indicate important differences compared to genus pattern.

The remaining five species of the genus Wohlfahrtia could be examined and yielded a homogenous genus pattern as well as species specific pattern variations. As in previous studies of MAS patterns, analyses were restricted to the thoracic segments of the third instar larvae. Size differences were reflected somewhat in the numbers of MAS assembling the pattern rows. The individual with the lowest number belonged to the smallest species ( $W$. indigens) but the larvae with the highest number did not belong to the largest species (Table 1).

Deviations of MAS numbers from the average genus count for each row were never larger than 2, except for W. nuba with one deviation of 3 MAS in Row 4.2. Wohlfahrtia bella, the species with the largest larvae had four deviations above average genus count. Wohlfahrtia nuba, a facultative parasite had six deviations of 2 or more MAS below average genus count. Wohlfahrtia villeneuvi, the one solely necrophagous species analyzed in this study, was not different from her facultative parasitic comrades. With an intermediate size the species also had an intermediate number of MAS and no apparent deviation in MAS numbers from the average (Tables 1 and 2). The only difference to the genus pattern was found in row 4.1a (Fig. 5). Necrophagous and facultative parasitic habits therefore do not seem to have a significant effect on the MAS pattern in Wohlfahrtia species.

The genera Sarcophaga and Wohlfahrtia belong to the family Sarcophagidae. Differentiation is easy in the first instar larvae of Paramacronychiinae and Sarcophaginae as in the second taxon the labrum is vestigial ${ }^{19}$. However, their third instar larvae have very similar external morphology ${ }^{27}$, so the differences in the MAS patterns discovered during the present research are all the more striking. The study presented here is therefore additional evidence for the suitability of MAS analysis for species determination in a variety of cyclorrhaphous Diptera.

For further improvement of the MAS method for species determination in dipteran larvae, the first steps into computerization were conducted in a previous study ${ }^{28}$. This approach will reduce researcher bias and facilitate the method. For a successful advancement, however, the analysis of many more larvae from a broader range of species and genera will be necessary.

\section{Materials and Methods}

Insects. Adult females of $W$. bella, $W$. indigens, $W$. nuba, W. trina and W. villeneuvi were attracted to decomposing chicken liver and collected by sweep net. Larvae of obligate parasite W. magnifica were collected directly from the host wounds. Detailed data regarding collecting locations in Greece, Iran and Israel are in Table 4. The first instar larvae were obtained by gently squeezing the abdomen of sedated females. Larvae from different females were reared separately in plastic containers $(150 \mathrm{ml})$ with small portions of chicken liver $(20-30 \mathrm{gr})$ as feeding medium. When the larvae reached the third instar they were killed by dousing with boiling water and stored in $70 \%$ ethanol. Unambiguous species identification was possible by breeding some larvae of each species to the adult form. Obtained male specimens were identified using the most recent key on the genus ${ }^{15}$. All maternal females and laboratory bred adult specimens were labeled and are available as voucher specimens in the 

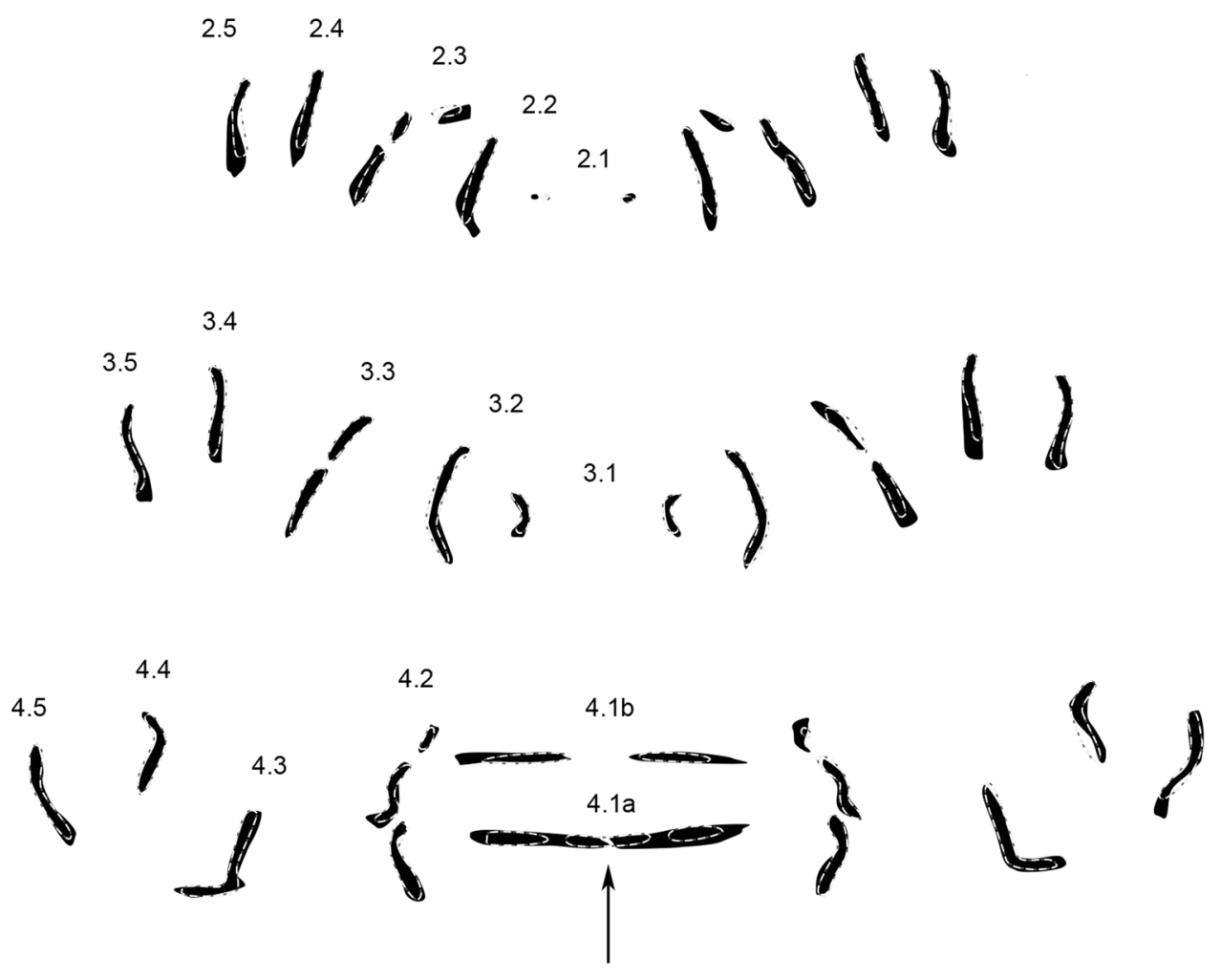

Figure 8. Condensed MAS pattern for Wohlfarthia villeneuvi (solid structures) superimposed with outlines of the genus pattern (dotted lines). Numbers indicate rows of transversal muscle attachment site patterns according to their location on and affiliation with a segment. Arrows indicate important differences compared to genus pattern.

\begin{tabular}{|c|c|c|c|c|c|c|c|}
\hline Row & 2.1 & 2.2 & 2.3 & 2.4 & \multicolumn{3}{|l|}{2.5} \\
\hline Genus $W$. & $2( \pm 1.1)$ & $16( \pm 2.1)$ & $15( \pm 2.7)$ & $12( \pm 1,9)$ & \multicolumn{3}{|l|}{$11( \pm 2.1)$} \\
\hline Genus $S$. & $0( \pm 0.5)$ & $12( \pm 2.6)$ & $13( \pm 2.9)$ & $11( \pm 2.7)$ & \multicolumn{3}{|l|}{$8( \pm 1.8)$} \\
\hline Row & 3.1 & 3.2 & 3.3 & 3.4 & \multicolumn{3}{|l|}{3.5} \\
\hline Genus $W$. & $6( \pm 0.9)$ & $19( \pm 2.2)$ & $17( \pm 2.5)$ & $13( \pm 1.7)$ & \multicolumn{3}{|l|}{$12( \pm 1.3)$} \\
\hline Genus $S$. & $4( \pm 1.1)$ & $14( \pm 2.4)$ & $14( \pm 2.9)$ & $12( \pm 2.8)$ & \multicolumn{3}{|l|}{$10( \pm 2.0)$} \\
\hline Row & 4.1a_center & 4.1a_side & $4.1 \mathrm{~b}$ & 4.2 & 4.3 & 4.4 & 4.5 \\
\hline Genus $W$. & $7( \pm 2.5)$ & $9( \pm 1.5)$ & $6( \pm 1.7)$ & $25( \pm 2.4)$ & $14( \pm 2.2)$ & $11( \pm 1.8)$ & $13( \pm 1.5)$ \\
\hline Genus $S$. & $5( \pm 2.3)$ & $7( \pm 2.1)$ & $6( \pm 2.2)$ & $17( \pm 3.4)$ & $11( \pm 2.2)$ & $9( \pm 2.5)$ & $9( \pm 1.9)$ \\
\hline
\end{tabular}

Table 3. Comparison of average MAS numbers in rows of Wohlfarthia (W.) and Sarcophaga (S.). All differences are significant (non-parametric Mann-Whitney U test).

insect collection of the Department of Ecology and Biogeography, Faculty of Biological and Veterinary Sciences, Nicolaus Copernicus University in Toruń, Poland.

Preparation. The larvae were measured to the nearest $0.1 \mathrm{~mm}$ using a dissecting microscope (Zeiss Stemi 2000C) with digital camera (Zeiss AxioCam ICc1) and measuring software (AxioVision). Larvae were opened along the dorsal midline and all muscle layers removed. The central rows of the MAS patterns correspond to the ventral center at the inside of the cuticula of each segment. All subsequent preparation and evaluation steps leading to the condensed patterns were performed as given in our previous publications ${ }^{23,26,29}$.

Data evaluation. Higher dipteran larvae are composed of a pseudocephalon and additional 11 segments. The first three segments are referred to as thoracic segments (t1-3), the following 7 are abdominal segments (a1-7) and the last is the anal division. For the study of MAS a plain designation of segments by numbers was chosen for convenience and clarity (Fig. 2). All rows in segments 2-4 were labeled according to our previous publication on Sarcophaga species (Niederegger et al. $2016^{26}$ ). The patterns were evaluated using Inkscape v. 0.91 (available under GPLv2 + from https://inkscape.org) and Adobe Photoshop ${ }^{\circledR}$ CS5 (Adobe Systems, Inc., San Jose, CA, USA); means and standard deviations were calculated using Microsoft ${ }^{\circledR}$ Office Excel ${ }^{\circledR} 2010$. 
2.5

3.4

$\left(\begin{array}{l}3.5 \\ i \\ i\end{array}\right.$

4.4

4.5

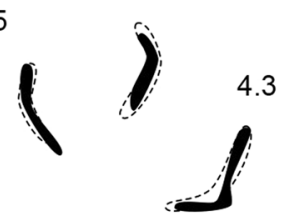

4.2

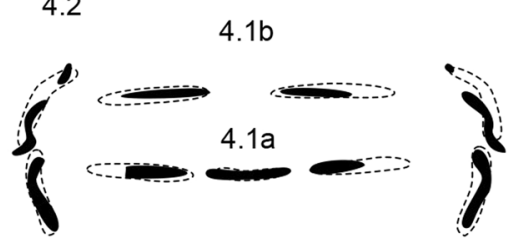

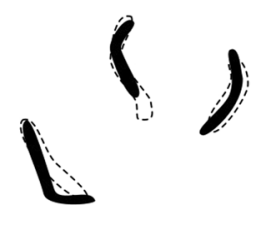

Figure 9. Genus pattern of Wohlfarthia (solid structures) superimposed with outlines of the genus pattern of Sarcophaga (dotted lines). Numbers indicate rows of transversal muscle attachment site patterns according to their location on and affiliation with a segment.

\begin{tabular}{|c|c|c|}
\hline Species & Location & $\begin{array}{l}\text { No. of } \\
\text { larvae }\end{array}$ \\
\hline Wohlfahrtia bella & $\begin{array}{l}\text { Iran, North Khorasan, Marghzar, } 1145 \text { m.a.s.l., } \\
37^{\circ} 03^{\prime} 52^{\prime \prime} \mathrm{N} 56^{\circ} 16^{\prime} 14^{\prime \prime} \mathrm{E} \text {, leg. KEiB Iran Expedition I }\end{array}$ & 8 \\
\hline Wohlfahrtia bella & $\begin{array}{l}\text { Iran, North Khorasan, Ru'in, } 1782 \text { m.a.s.l., } \\
37^{\circ} 11^{\prime} 47^{\prime \prime} \mathrm{N} 57^{\circ} 29^{\prime} 02^{\prime \prime} \mathrm{E} \text {, leg. KEiB Iran Expedition I }\end{array}$ & 3 \\
\hline Wohlfahrtia indigens & $\begin{array}{l}\text { Iran, Kerman, Anduhjerd, } 757 \text { m.a.s.l., } \\
30^{\circ} 14^{\prime} 15^{\prime \prime} \mathrm{N} 57^{\circ} 47^{\prime} 14^{\prime \prime} \mathrm{E} \text {, leg. KEiB Iran Expedition II }\end{array}$ & 3 \\
\hline Wohlfahrtia indigens & $\begin{array}{l}\text { Iran, Kerman, Shahdad, } 420 \text { m.a.s.l., } \\
30^{\circ} 27^{\prime} 39^{\prime \prime} \mathrm{N} 57^{\circ} 43^{\prime} 19^{\prime \prime} \mathrm{E} \text {, leg. KEiB Iran Expedition II }\end{array}$ & 7 \\
\hline Wohlfahrtia magnifica & $\begin{array}{l}\text { Greece, Thrace, Kardamos, } 500 \text { m.a.s.l., } \\
25^{\circ} 37^{\prime} 30^{\prime \prime} \mathrm{E}, 41^{\circ} 16^{\prime} 43^{\prime \prime} \mathrm{N} \text {, leg. S. Sotiraki }\end{array}$ & 7 \\
\hline Wohlfahrtia magnifica & $\begin{array}{l}\text { Iran, Fars, Dasht Arzan, } 1990 \text { m.a.s.l. } \\
51^{\circ} 58^{\prime} 33^{\prime \prime} \mathrm{N} 29^{\circ} 39^{\prime} 21^{\prime \prime} \mathrm{E} \text {, leg. K. Akbarzadeh }\end{array}$ & 6 \\
\hline Wohlfahrtia nuba & $\begin{array}{l}\text { Iran, North Khorasan, Sarcheshmeh, } 932 \text { m.a.s.l., } \\
37^{\circ} 38^{\prime} 00^{\prime \prime} \mathrm{N} 57^{\circ} 24^{\prime} 25^{\prime \prime} \mathrm{E} \text {, leg. KEiB Iran Expedition I }\end{array}$ & 3 \\
\hline Wohlfahrtia nuba & $\begin{array}{l}\text { Iran, North Khorasan, Darband, } 1129 \text { m.a.s.l., } \\
37^{\circ} 14^{\prime} 10^{\prime \prime} \mathrm{N} 56^{\circ} 49^{\prime} 50^{\prime \prime} \mathrm{E} \text {, leg. KEiB Iran Expedition III }\end{array}$ & 11 \\
\hline Wohlfahrtia trina & $\begin{array}{l}\text { Israel, Ein Avdat NP, Nahal Zin, } 328 \text { m.a.s.l., } \\
30^{\circ} 50^{\circ} 26^{\prime \prime} \mathrm{N} 34^{\circ} 48^{\prime} 35^{\prime \prime} \mathrm{E} \text {, leg. K. Szpila }\end{array}$ & 4 \\
\hline Wohlfahrtia trina & $\begin{array}{l}\text { Iran, Khorasan-e-Razavi, Mir Haj, } 1042 \text { m.a.s.l., } \\
36^{\circ} 39^{\prime} 41^{\prime \prime} \mathrm{N} 56^{\circ} 38^{\prime} 50^{\prime \prime} \mathrm{E} \text {, leg. KEiB Iran Expedition I }\end{array}$ & 4 \\
\hline Wohlfahrtia trina & $\begin{array}{l}\text { Iran, Khorasan-e-Razavi, Mir Haj, } 1042 \text { m.a.s.l., } \\
36^{\circ} 39^{\prime} 41^{\prime \prime} \mathrm{N} 56^{\circ} 38^{\prime} 50^{\prime \prime} \mathrm{E} \text {, leg. KEiB Iran Expedition I }\end{array}$ & 4 \\
\hline Wohlfahrtia villeneuvi & $\begin{array}{l}\text { Iran, Kerman, Tachrud, } 1711 \text { m.a.s.l., } \\
29^{\circ} 23^{\prime} 31^{\prime \prime} \mathrm{N} 57^{\circ} 52^{\prime} 36^{\prime \prime} \mathrm{E} \text {, leg. KEiB Iran Expedition II }\end{array}$ & 7 \\
\hline Wohlfahrtia villeneuvi & $\begin{array}{l}\text { Israel, Ein Avdat NP, Ein Akev Spring, } 404 \text { m.a.s.l., } \\
30^{\circ} 4816^{\prime \prime} \mathrm{N} 3448^{\prime} 48^{\prime \prime} \mathrm{E} \text {, leg. K. Szpila }\end{array}$ & 5 \\
\hline
\end{tabular}

Table 4. Collecting locations for larvae.

Statistical comparison. The Wohlfahrtia genus pattern was compared to the Sarcophaga genus pattern as both genera belong to the family Sarcophagidae. More than half of the rows showed non-normal distribution in the numbers of MAS per row, the statistical analysis was therefore performed using a non-parametric MannWhitney $\mathrm{U}$ test for all rows. 


\section{Data availability}

The data that support the findings of this study are available from the corresponding author, SN, upon reasonable request.

Received: 28 May 2019; Accepted: 19 November 2019;

Published online: 16 December 2019

\section{References}

1. Ge, Y. Q., Zhang, D. \& Pape, T. A new species of Wohlfahrtia Brauer \& Bergenstamm (Diptera: Sarcophagidae) from northwestern China, with three new synonymies and a pictorial synopsis. Zootaxa 4434, 130-140, https://doi.org/10.11646/zootaxa.4434.1.8 (2018).

2. Hall, M. J. R. \& Farkas, R. Traumatic myiasis of humans and animals. Pages 751-768 in: Papp, L. \& Darvas, B. (editors) Contributions to a Manual of Palaearctic Diptera (with Special Reference to Flies of Economic Importance), Vol. 1. General and Applied Dipterology. (Budapest, Hungary: Science Herald; 2000).

3. Hall, M. J. R., Wall, R. L. \& Stevens, J. R. Traumatic Myiasis: A Neglected Disease in a Changing World. Annual Review of Entomology 61, 159-176, https://doi.org/10.1146/annurev-ento-010715-023655 (2016).

4. Al-Mesbah, H., Al-Osaimi, Z. \& El-Azazy, O. M. E. Forensic entomology in Kuwait: The first case report. Forensic Science International 206, E25-E26, https://doi.org/10.1016/j.forsciint.2010.07.013 (2011).

5. Hall, M. J. R. et al. Morphological and mitochondrial DNA characters for identification and phylogenetic analysis of the myiasiscausing flesh fly Wohlfahrtia magnifica and its relatives, with a description of Wohlfahrtia monegrosensis sp $\mathrm{n}$. Wyatt \& Hall. Medical and Veterinary Entomology 23, 59-71, https://doi.org/10.1111/j.1365-2915.2008.00779.x (2009).

6. Tantawi, T. I., Elkady, E. M., Greenberg, B. \& ElGhaffar, H. A. Arthropod succession on exposed rabbit carrion in Alexandria, Egypt. Journal of Medical Entomology 33, 566-580, https://doi.org/10.1093/jmedent/33.4.566 (1996).

7. Tawfik, M. S. Ecological studies on some desert flies in Egypt. Indian Journal of Entomology 31, 201-221 (1969).

8. Khedre, A. M. Growth rates of fleshfly Wohlfahrtia nuba (Wied.) (Diptera: Sarcophagidae) on different body tissues and post feeding dispersal of the larvae: implications for forensic Entomology. Egyptian Journal of Zoology 46, 135-149 (2006).

9. Pape, T. The Sarcophagidae (Diptera) of Fennoscandia and Denmark. Fauna Entomologica Scaninavica 19, 1-203 (Brill, E.J., 1987).

10. Verves, Y. G. To the knowledge of the subfamilies of the Sarcophagidae (Diptera). International. Journal of Dipterological Research 9 , 243-244 (1998)

11. Buenaventura, E., Szpila, K., Cassel, B. K., Wiegmann, M. \& Pape, T. Anchored hybrid enrichment challenges the traditional classification of flesh flies (Diptera: Sarcophagidae). Systematic Entomology early view, https://doi.org/10.1111/syen.12395 (2019).

12. Piwczyński, M. et al. Molecular phylogeny of Miltogramminae (Diptera: Sarcophagidae): Implications for classification, systematics and evolution of larval feeding strategies. Molecular Phylogenetics and Evolution 116, 49-60, https://doi.org/10.1016/j. ympev.2017.07.001 (2017).

13. Piwczyński, M., Szpila, K., Grzywacz, A. \& Pape, T. A large-scale molecular phylogeny of flesh flies (Diptera: Sarcophagidae). Systematic Entomology 39, 783-799, https://doi.org/10.1111/syen.12086 (2014).

14. Rohdendorf, B. B. The Palaearctic species of the genus Wohlfahrtia B.B. (Diptera, Sarcophagidae). Entomologiceskoe Obozrenie 35, 201-229 [In Russian with English subtitle.] (1956).

15. Verves, Y. G. 64 h. Sarcophaginae. In: Die Fliegen der palaearktischen Region Vol. 11, Lieferung 330 (ed E. Lindner) 297-440 (1985).

16. Khedre, A. M. Scanning electron microscopy of the larval morphological characteristics of Wohlfahrtia nuba (Wiedmann) and Parasarcophaga aegyptiaca (Salem) (Diptera: Sarcophagidae). Egyptian Journal of Zoology 33, 237-249 (1999).

17. Ruiz-Martinez, I. et al. Scanning electron microscope study of Wohlfahrtia magnifica (Schiner, 1862) (Diptera: Sarcophagidae). I. Structures with parasitic and possible taxonomic meaning. Scanning Microscopy 4, 103-109 (1990).

18. Ruiz-Martinez, I., Soler-Cruz, M. D., Benitez-Rodriguez, R., Perez-Jimenez, J. M. \& Diaz-Lopez, M. Postembryonic development of Wohlfahrtia magnifica (Schiner, 1862) (Diptera: Sarcophagidae). Journal of Parasitology 75, 531-539 (1989).

19. Szpila, K., Hall, M. J. R., Wardhana, A. H. \& Pape, T. Morphology of the first instar larva of obligatory traumatic myiasis agents (Diptera: Calliphoridae, Sarcophagidae). Parasitology Research 113, 1629-1640, https://doi.org/10.1007/s00436-014-3808-x (2014).

20. Zumpt, F. Myiasis in man and animals in the Old World; a textbook for physicians, veterinarians, and zoologists. (Butterworths, 1965).

21. Kutty, S. N., Pape, T., Wiegmann, B. M. \& Meier, R. Molecular phylogeny of the Calyptratae (Diptera: Cyclorrhapha) with an emphasis on the superfamily Oestroidea and the position of Mystacinobiidae and McAlpine's fly. Systematic Entomology 35, 614-635, https://doi.org/10.1111/j.1365-3113.2010.00536.x (2010).

22. Jordaens, K. et al. Identification of forensically important Sarcophaga species (Diptera: Sarcophagidae) using the mitochondrial COI gene. International Journal of Legal Medicine 127, 491-504, https://doi.org/10.1007/s00414-012-0767-6 (2013).

23. Niederegger, S. \& Spieß, R. Cuticular muscle attachment sites as a tool for species determination in blowfly larvae. Parasitology Research 110, 1903-1909, https://doi.org/10.1007/s00436-011-2716-6 (2012).

24. Niederegger, S. \& Spieß, R. Muscle attachment sites of Phormia regina (Meigen). Parasitology Research 113, 4313-4314, https://doi. org/10.1007/s00436-014-4146-8 (2014).

25. Niederegger, S., Szpila, K. \& Mall, G. Muscle attachment site (MAS) patterns for species determination in European species of Lucilia (Diptera: Calliphoridae). Parasitology Research 114, 851-859, https://doi.org/10.1007/s00436-014-4248-3 (2015).

26. Niederegger, S., Szpila, K. \& Mall, G. Muscle attachment site (MAS) patterns for species determination in five species of Sarcophaga (Diptera: Sarcophagidae). Parasitology Research 115, 241-247, https://doi.org/10.1007/s00436-015-4740-4 (2016).

27. Szpila, K., Richet, R. \& Pape, T. Third instar larvae of flesh flies (Diptera: Sarcophagidae) of forensic importance-critical review of characters and key for European species. Parasitology Research 114, 2279-2289, https://doi.org/10.1007/s00436-015-4421-3 (2015).

28. Niederegger, S., Döge, K.-P., Peter, M., Eickhölter, T. \& Mall, G. Connecting the Dots: From an Easy Method to Computerized Species Determination. Insects 8(52), 16, https://doi.org/10.3390/insects8020052 (2017).

29. Niederegger, S., Miroschnikow, A. \& Spieß, R. Marked for life: muscle attachment site patterns in blowfly larvae are constant throughout development. Parasitology Research 112, 347-355, https://doi.org/10.1007/s00436-012-3142-0 (2013).

\section{Acknowledgements}

We are grateful to Dr. Kourosh Arzamani (North Khorasan University of Medical Sciences) and Dr. Abbas Aghaei Afshar (Kerman University of Medical Science) for excellent help in organizing collecting trips. Dr. Smaragda Sotiraki (Veterinary Research Institute, Thesalloniki) and Dr. Martin Hall (NHM, London) helped with material of W. magnifica from Greece. Parts of this work were financially supported by the Polish National Science Centre (grant no. 2012/07/B/NZ8/00158).

\section{Author contributions}

S.N. and K.S. wrote the main manuscript text, K.S. prepared Fig. 1, S.N. prepared Figs. 2-9. K.S. and K.A. provided the materials. All authors contributed to revisions and accepted the final version. 


\section{Competing interests}

The authors declare no competing interests.

\section{Additional information}

Correspondence and requests for materials should be addressed to S.N.

Reprints and permissions information is available at www.nature.com/reprints.

Publisher's note Springer Nature remains neutral with regard to jurisdictional claims in published maps and institutional affiliations.

(c) (i) Open Access This article is licensed under a Creative Commons Attribution 4.0 International License, which permits use, sharing, adaptation, distribution and reproduction in any medium or format, as long as you give appropriate credit to the original author(s) and the source, provide a link to the Creative Commons license, and indicate if changes were made. The images or other third party material in this article are included in the article's Creative Commons license, unless indicated otherwise in a credit line to the material. If material is not included in the article's Creative Commons license and your intended use is not permitted by statutory regulation or exceeds the permitted use, you will need to obtain permission directly from the copyright holder. To view a copy of this license, visit http://creativecommons.org/licenses/by/4.0/.

(c) The Author(s) 2019 